\title{
Nasal Versus Oronasal Mask in Home Mechanical Ventilation: The Preference of Patients as a Strategy for Choosing the Interface
}

\author{
Ramón Fernandez MD, Cristina Cabrera MD, Gemma Rubinos MD, Ana Pando MD, \\ Rosa Galindo MD, Francisco Rodríguez MD, Francisco Lopez MD, \\ Isidro Gonzalez MD, and Pere Casan MD
}

\begin{abstract}
INTRODUCTION: In home mechanical ventilation (HMV), the mask is a key factor for patient comfort and therapeutic adherence. There is no evidence on the best strategy for choosing the mask in HMV. OBJECTIVE: To explore patient preference when prescribing the mask for HMV treatment and assess its relationship with effectiveness. METHODS: A prospective study with repeated measures in stable patients receiving home nocturnal ventilation. Alternating oronasal mask (ONM) and nasal mask (NM) were tested in day and overnight sessions, with arterial blood gas measured and $\mathrm{S}_{\mathrm{pO}_{2}}$ monitored. At the end of each evening session, patients rated interface comfort using a visual analog scale. At 3 months we evaluated adherence and effectiveness of the treatment. RESULTS: Twenty-nine subjects (mean \pm SD age $65 \pm 13$ y, 44\% male) completed the study. Initial functional values were $\mathrm{P}_{\mathrm{CO}_{2}} 57.4 \pm 5.2 \mathrm{~mm} \mathrm{Hg}$ and time with $\mathrm{S}_{\mathrm{pO}_{2}}<90 \%$ (T90) $81.5 \pm 9.5 \%$. Both ONM and NM significantly decreased $\mathrm{P}_{\mathrm{CO}_{2}}$ and T90. Over a third (38\%) of our subjects preferred ONM, while NM was deemed more comfortable in general. At 3 months, effectiveness and adherence showed no differences between those treated with NM or ONM. CONCLUSIONS: Patient choice is an effective criterion for selecting the interface in HMV treatment. Key words: home mechanical ventilation; noninvasive ventilation. [Respir Care 2012;57(9):1413-1417. () 2012 Daedalus Enterprises]
\end{abstract}

\section{Introduction}

In the process of adaptation to noninvasive ventilation (NIV), one of the most important decisions is the choice of mask that acts as the interface between the patient and the ventilator. This is a key factor for patient comfort and the success of long-term treatment. ${ }^{1}$ The different models of

Drs Fernandez, Rubinos, Pando, Rodríguez, Lopez, and Casan are affiliated with Servicio de Neumologia, Hospital Universitario Central de Asturias, Facultad de Medicina Universidad de Oviedo, Oviedo, Asturias, Spain. Drs Cabrera, Galindo, and Gonzalez are affiliated with Servicio de Neumología, Hospital Universitario de Canarias, La Laguna, Santa Cruz de Tenerife, Spain.

Dr Fernandez presented a version of this paper at the meeting of the Spanish Respiratory Society, held June 17-20, 2011, in Oviedo, Spain.

Correspondence: Ramón Fernandez MD, Servicio de Neumologia, Hospital Universitario Central de Asturias, Facultad de Medicina Universidad de Oviedo, Oviedo, Asturias, Spain. Email: enelllano@gmail.com.

DOI: $10.4187 /$ respcare. 01500 masks can be classified as those that cover only the nose (nasal mask [NM]), the nose and mouth (oronasal mask [ONM]), nasal pillows, and mouthpieces. ${ }^{1}$ The market currently offers a wide range of options, including custom made interfaces for highly selected patients. ${ }^{2}$ In deciding which mask to use, the clinician has to evaluate the most effective mask in conjunction with patient comfort.

Traditionally, the NM has been considered preferable for home mechanical ventilation (HMV) and the ONM for acute NIV. ${ }^{3}$ While the use of ONM for acute NIV seems well established according to the results of clinical studies, ${ }^{4}$ there are no studies providing evidence on the impact that the choice of either mask has on effectiveness and therapeutic adherence in HMV; patient preference has not been explored, and there are no definite recommendations on the choice of interface.

We hypothesized that a combination of comfort and effectiveness criteria in mask selection for HMV could improve adherence and substantially change the usage profile of the interfaces commonly used in clinical practice (NM and ONM). The study aimed to explore personal 


\section{Nasal Versus Oronasal Mask in Home Mechanical Ventilation}

preferences in the choice of the mask during the process of adaptation to HMV and its relationship to effectiveness in the short and long term. Secondarily, we assessed the impact of this preference on prescription and its influence on programmed ventilator parameters.

\section{Methods}

The study was performed at the respiratory units at Hospital Universitario de Canarias, La Laguna, Tenerife, Spain, and Hospital Universitario Central de Asturias, Oviedo, Asturias, Spain, both of which have experience in home NIV. The study design was prospective, with repeated measures and paired data. The subjects were included consecutively during a period of 4 months, from August to November 2009 in one center, and from March to June 2010 in the other. The study was approved by the ethics committees of both centers, and all participants signed informed consent for inclusion in the study.

The inclusion criteria were: stable patients eligible for NIV treatment, without previous experience of ventilation, with $\mathrm{P}_{\mathrm{CO}_{2}}>50 \mathrm{~mm} \mathrm{Hg}$, and scheduled for home nocturnal treatment. The exclusion criteria were: $\mathrm{pH}<7.35$, cognitive disorders, severe uncontrolled comorbidity, and clinical prediction of ventilation required during $>12$ hours a day.

The following pressure ventilators were adapted for NIV: Vivo 30 and Vivo 40 (Breas Medical, Mölnlycke. Sweden), and VPAP III and VPAP IV (ResMed, Sydney, Australia). The ventilatory mode was spontaneous/timed with backup breathing frequency slightly lower than spontaneous breathing rate. In all cases the mask used had an intentional leak circuit. NM and ONM were used alternately in a predetermined order, reversed for each new case. The most appropriate mask size was applied in each case, to minimize leakage. Subjects attended 2-hour day sessions and used each mask on successive days, with arterial blood gas tested after each session, and evening sessions with pulse oximetry. The inspiratory and expiratory positive airway pressures were titrated empirically in the day sessions, to maximize comfort (this was determined by asking the subject about his/her comfort level at different times during the process of adaptation), and effectiveness was arbitrarily defined using the following criteria: decrease in day $\mathrm{P}_{\mathrm{CO}_{2}}$ of at least $5 \mathrm{~mm} \mathrm{Hg}$ and/or decrease of at least 30 points in the percentage of nocturnal time with $\mathrm{S}_{\mathrm{pO}_{2}}<90 \%$ (T90). At the end of each evening session the subject was asked to rate the mask on a visual analog scale (0 to 10$)$, responding to the following request: "Please indicate your level of comfort on breathing through the mask." After testing the 2 masks, the subject was asked to choose one for his/her home treatment. For interface prescription, subject preference was prioritized when both masks met the criteria of effectiveness,

\section{QUICK LOOK}

\section{Current knowledge}

A major factor in the success of home noninvasive ventilation is patient acceptance of the interface. Mask comfort plays a primary role in patient adherence to NIV treatment.

\section{What this paper contributes to our knowledge}

Patient preference is a key component of NIV acceptance. The patient's subjective assessment of comfort improves NIV adherence and should play a major role in the choice of the NIV interface.

otherwise the most effective model was prescribed. After 3 months, effectiveness was assessed according to arterial blood gas and home nocturnal $\mathrm{S}_{\mathrm{pO}_{2}}$ values, home ventilation time, changes of interface and dropout.

Nocturnal $\mathrm{S}_{\mathrm{pO}_{2}}$ values were measured continuously during sleep in the supine position, using a finger tip infrared pulse oximeter (Pulsox-3iA, Konica Minolta Sensing, Osaka, Japan), provided with a finger clip and a multisite probe (SR-5C, $0.3 \mathrm{~m}$, Konica Minolta Sensing, Osaka, Japan). The $\mathrm{S}_{\mathrm{pO}_{2}}$ readings and pulse rate were displayed on a computer screen with an interface unit (IF-3, Konica Minolta Sensing, Osaka, Japan), and an interface cable (I/F cable, Konica Minolta Sensing, Osaka, Japan), via software (Pulsox DS-3, Konica Minolta Sensing, Osaka, Japan).

The NM models used were: FlexiFit 405 (Fisher \& Paykel Healthcare, Auckland, New Zealand), with over-the-nose silicone seal, elbow exhalation port, and a dead space of $88 \mathrm{~mL}$; and Ultra Mirage II (ResMed, San Diego, California), with elbow exhalation port and a dead space of $130 \mathrm{~mL}$. The ONM models used were: Forma (Fisher \& Paykel Healthcare, Auckland, New Zealand), covering mouth and nose, with nasal bridge exhalation port; FlexiFit 431 (Fisher \& Paykel Healthcare, Auckland, New Zealand), with silicone sheath covering the nose and mouth, and elbow exhalation port; and Wizard-Fit (Apex, Taiwan), covering the nose and mouth, with elbow exhalation port. The ONM dead space varied between $108 \mathrm{~mL}$ and $192 \mathrm{~mL}$, depending on the model.

The results are presented as mean and standard deviation for quantitative variables, and percentages for qualitative variables. We used the Student $t$ test to compare the means of quantitative variables, and chi-square for qualitative variables. We used the Kolmogorov-Smirnov test to check the fit of the variables to normal distribution. Differences with a $P$ value of $<.05$ were considered statistically significant. 
Table 1. Results of the Adaptation Process to Nasal vs Oronasal Mask

\begin{tabular}{|c|c|c|c|}
\hline & $\begin{array}{l}\text { Nasal Mask } \\
\quad(n=29)\end{array}$ & $\begin{array}{c}\text { Oronasal } \\
\text { Mask } \\
(n=29)\end{array}$ & $P$ \\
\hline $\begin{array}{l}\mathrm{P}_{\mathrm{aCO}_{2}} \text { after NIV (2 h day session), } \\
\mathrm{mm} \mathrm{Hg}\end{array}$ & $47.3 \pm 6.3$ & $50.2 \pm 5.1$ & .87 \\
\hline $\mathrm{pH}$ after NIV (2 h day session) & $7.40 \pm 0.30$ & $7.40 \pm 0.28$ & .81 \\
\hline $\begin{array}{l}\mathrm{HCO}_{3}^{-} \text {after NIV ( } 2 \text { h day session), } \\
\mathrm{mmol} / \mathrm{L}\end{array}$ & $29.3 \pm 3.2$ & $32.2 \pm 1.8$ & .23 \\
\hline T90 after NIV (night session), \% & $39.4 \pm 20.3$ & $36.6 \pm 29.5$ & .67 \\
\hline IPAP, $\mathrm{cm} \mathrm{H}_{2} \mathrm{O}$ & $13.7 \pm 2.7$ & $15.4 \pm 2.4$ & .02 \\
\hline EPAP, $\mathrm{cm} \mathrm{H}_{2} \mathrm{O}$ & $6.3 \pm 1.1$ & $6.2 \pm 1.2$ & .89 \\
\hline Respiratory rate, breaths/min & $15.5 \pm 3.1$ & $14.5 \pm 2.3$ & .71 \\
\hline Comfort score, analog scale & $6.9 \pm 2.3$ & $5.3 \pm 2.3$ & .01 \\
\hline \multicolumn{4}{|c|}{$\begin{array}{l}\text { Values are mean } \pm \mathrm{SD} \\
\mathrm{NIV}=\text { noninvasive ventilation } \\
\mathrm{T} 90=\text { percentage of time with } \mathrm{S}_{\mathrm{pO}_{2}}<90 \% \text { during nocturnal ventilation } \\
\mathrm{IPAP}=\text { inspiratory positive airway pressure } \\
\mathrm{EPAP}=\text { expiratory positive airway pressure }\end{array}$} \\
\hline
\end{tabular}

\section{Results}

Of the initial 30 candidates, one patient refused treatment at the start of the 3-month adaptation process. The process was carried out by 29 subjects (44\% male), mean \pm SD age $65 \pm 13$ years. Diagnoses were: 20 obesity hypoventilation syndrome, 4 chest wall pathology ( 2 with post-tuberculosis sequelae and thoracoplasty, and 2 with diaphragmatic paralysis), 3 neuromuscular disease (2 had AMS and one had Werdnig-Hoffman spinal atrophy), and 2 subjects had COPD. Nocturnal polygraphy was performed in all 20 subjects with obesity hypoventilation syndrome; 16 (80\%) had an apnea-hypopnea severity index above 5 , and a mean $\pm \mathrm{SD}$ value of $50 \pm 32$.

Baseline functional values were: $\mathrm{P}_{\mathrm{CO}_{2}} 57.4 \pm 5.2 \mathrm{~mm} \mathrm{Hg}$, T90 $81.5 \pm 9.5 \%$. At the end of day and evening adaptation sessions, we found significant decreases in $\mathrm{P}_{\mathrm{CO}_{2}}$ and T90 with the use of either mask, and no significant differences between NM and ONM (Table 1). In 11 cases the ONM was preferred (38\%), but actually prescribed for 14 subjects $(48 \%)$, because in 3 cases $(10 \%)$ the criterion of effectiveness was prioritized over comfort. The NM comfort score was significantly higher than that of the ONM (see Table 1).

At 3 months, 4 subjects (13\%, 3 with NM and 1 ONM) had discontinued treatment: one had COPD, and 3 had obesity hypoventilation syndrome. There was one change from NM to nasal pillows, due to nasal bridge erosion (this subject also required heated humidification), and one subject treated with ONM who initially preferred NM requested a change of mask. Of the 23 subjects who completed the 3-month adaptation process with their initial interfaces, daytime $\mathrm{P}_{\mathrm{CO}_{2}}$ and T90 values showed no sig- nificant differences between NM and ONM users (Table 2). Mean nocturnal ventilation time was greater than 7 hours, with no significant differences between groups.

\section{Discussion}

In our subjects, NM were generally deemed more comfortable than ONM, but $40 \%$ preferred to be treated with ONM. We found no significant differences between the 2 interfaces in effectiveness, the process of adaptation, or long-term use. Using a strategy that combines patient preference and effectiveness, ONM requirement rose to $48 \%$ of treated cases.

Interface comfort in NIV is crucial to achieve good tolerance and compliance, and thus long-term effectiveness. The choice of mask is one of the key decisions to be made by the attending clinician. ${ }^{1}$ While studies on the management of acute patients have explored the effectiveness of different types of interfaces and the strategy to be implemented is well established, few such studies have been performed in chronic patients, so there is great variability in clinical practice.

Navalesi et $\mathrm{al}^{5}$ studied 26 patients randomly assigned to receive NM, ONM, or nasal pillows. NM were better tolerated, while ONM proved more effective; the authors did not analyze nocturnal ventilation or long-term results. Our results are consistent with the finding that NM is generally better tolerated, but showed no significant differences in effectiveness. This discrepancy may be explained by a methodological difference: in the study by Navalesi et al, the trial period with each mask lasted $30 \mathrm{~min}$, compared with $120 \mathrm{~min}$ in our series.

More recently, Willson et $\mathrm{al}^{6}$ studied 16 patients previously treated with NIV using NM; on one night, treatment with ONM was tested to assess comfort with this mask, and effectiveness according to polysomnographic criteria. There were no differences in effectiveness in the polysomnographic variables analyzed, and NM was found to be more comfortable. In this work, the study population was treated with HMV using NM before the study.

In general, according to previous studies ${ }^{5,6}$ and our own results, greater comfort is found with NM. However, a high percentage of our subjects preferred to be treated with ONM. Some authors use ONM when they detect problems in NM ventilation. ${ }^{7}$ Our results suggest that a combination of effectiveness and patient preference from the outset may be a more appropriate strategy.

Traditionally, greater effectiveness has been attributed to ONM, due to its greater ability to prevent oral leaks. In our study, leakage was not measured, but similar effectiveness between the 2 masks suggests that the ventilator could compensate for excess oral leaks when the NM was used, as suggested by some authors ${ }^{8}$; in our study this was 
Table 2. Follow-up Results at 3 Months

\begin{tabular}{|c|c|c|c|}
\hline & $\begin{array}{l}\text { Nasal Mask } \\
\quad(n=11)\end{array}$ & $\begin{array}{c}\text { Oronasal } \\
\text { Mask } \\
(n=12)\end{array}$ & $P$ \\
\hline Age, y & $67.6 \pm 12.29$ & $63.8 \pm 11.1$ & .43 \\
\hline Male, no. & 3 & 7 & .045 \\
\hline Female, no. & 8 & 5 & ND \\
\hline \multicolumn{4}{|l|}{ Underlying Disease } \\
\hline Obesity-hypoventilation syndrome & 10 & 7 & ND \\
\hline Neuromuscular disease & 0 & 2 & ND \\
\hline Chest disease & 1 & 2 & ND \\
\hline COPD & 0 & 1 & ND \\
\hline Initial $\mathrm{P}_{\mathrm{aCO}_{2}}, \mathrm{~mm} \mathrm{Hg}$ & $55.0 \pm 12.5$ & $54.5 \pm 8.6$ & .83 \\
\hline Initial $\mathrm{T} 90, \%$ & $79.8 \pm 22.3$ & $79.8 \pm 1.8$ & .84 \\
\hline $\mathrm{P}_{\mathrm{CO}_{2}}$ after 3 months of NIV, $\mathrm{mm} \mathrm{Hg}$ & $44.3 \pm 3.5$ & $44.2 \pm 2.6$ & .74 \\
\hline $\mathrm{pH}$ after 3 months of NIV & $7.40 \pm 0.004$ & $7.40 \pm 0.02$ & .88 \\
\hline $\mathrm{HCO}_{3}{ }^{-}$after 3 months of NIV, mmol/L & $27.5 \pm 1.7$ & $27.3 \pm 1.5$ & .81 \\
\hline $\mathrm{T} 90$ at 3 months $\left(\mathrm{S}_{\mathrm{pO}_{2}}\right), \%$ & $3.4 \pm 4.5$ & $8.1 \pm 6.1$ & .25 \\
\hline Daily NIV time & $7 \mathrm{~h} 6 \mathrm{~min}$ & $7 \mathrm{~h} 20 \mathrm{~min}$ & .35 \\
\hline \multicolumn{4}{|c|}{$\begin{array}{l} \pm \text { Values are mean } \pm \text { SD. } \\
\mathrm{ND}=\text { no data: not calculated because of inadequate sample size } \\
\mathrm{NIV}=\text { noninvasive ventilation } \\
\mathrm{T} 90=\text { percentage of time with } \mathrm{S}_{\mathrm{PO}_{2}}<90 \% \text { during nocturnal ventilation }\end{array}$} \\
\hline
\end{tabular}

not demonstrated. To confirm this supposition, leakage would have to be measured with each interface used.

There is a noticeable difference between NM and ONM in the dead space they provide, and this difference could influence the effectiveness of the interface. In a lung model, Saatci et $\mathrm{al}^{9}$ demonstrated that the dynamic dead space in ONM with a leak port was very similar to NM and was related to the location of this leak port and the use of continuous pressure in the expiratory phase. These results were confirmed by Couvelier et al ${ }^{10}$ in a clinical trial.

Although not all studies on HMV report which masks were used, it seems clear that NM is the most common choice. ${ }^{7,11,12}$ According to our results, prioritizing patient preference for prescription would increase ONM use to almost 50\%, which represents a substantial change in the use profile of this interface.

In patients who require long-term nocturnal mechanical ventilation, treatment adherence is critical to effectiveness. Criner et al $^{13}$ reported $65 \%$ adherence, with an average of 4.5 hours per night. More recently, Priou et al $^{7}$ rated compliance at $80 \%$, with ventilation time of approximately 7 hours per night, and attributed this to factors associated with improved comfort of the NIV masks and devices. In our series, at 3 months, adherence to treatment was $86 \%$, with an average ventilation time of more than 7 hours per night. The strategy of involving the patient in choosing the interface may positively affect therapeutic adherence.

Possible limitations of our study include the fact that the subjects were ventilated with different ONM and NM models, but we believe that the careful individual titration of the inspiratory and expiratory airway pressure parameters and the general methodology employed minimize this impact on results. Comparison with the few existing studies addressing this problem is difficult because the methodology and patient characteristics differ, with a diagnostic predominance of obesity hypoventilation syndrome in our study. The criteria for effectiveness in the process of adaptation were arbitrarily established with undemanding limits based on the values of $\mathrm{P}_{\mathrm{CO}_{2}}$ and T90. There are no clear references in the literature on this point, and our intention was to maximize comfort. At 3 months, the improvement in T90 and $\mathrm{P}_{\mathrm{CO}_{2}}$ was much greater than at the time of adaptation, and therefore we consider that greater longterm effectiveness was achieved when comfort was maximized. However, assessing effectiveness by means of these 2 parameters has certain limitations, since gasometry was performed during the daytime, and nocturnal pulse oximetry does not directly measure the response to ventilation.

Another limitation of the study was the lack of homogeneity in underlying disease of the study population. We chose to study a population of patients scheduled to receive mechanical ventilation only at night: such patients are usually supplied with a single mask, and therefore a strategy to select the most appropriate could have a great impact on treatment. Our results are not applicable to patients requiring more prolonged $(>12 \mathrm{~h} / \mathrm{d})$ ventilation time, and, usually, different types of mask in the same patient. Lastly, the present study provides no information on other types of interfaces (nasal pillows and custommade masks). 


\section{Nasal Versus Oronasal Mask in Home Mechanical Ventilation}

\section{Conclusions}

To our knowledge, this is the first work to propose that mask prescription for HMV should take patient preference into account. Given the favorable results in sustained therapeutic compliance and effectiveness, we conclude that patient comfort could be the most effective criterion for interface selection in HMV treatment. Further studies with a randomized design are required to support this conclusion.

\section{REFERENCES}

1. Elliott MW. The interface: crucial for successful noninvasive ventilation. Eur Respir J 2004;23(1):7-8.

2. Robert D, Argaud L. Clinical review: long-term noninvasive ventilation. Crit Care 2007;11(2):210

3. Schönhofer B, Sortor-Leger S. Equipment needs for noninvasive mechanical ventilation. Eur Respir J 2002;20(4):1029-1036.

4. Girault C, Briel A, Benichou J, Hellot MF, Dachraoui F, Tamion F, Bonmarchand $\mathrm{G}$. Interface strategy during noninvasive positive pressure ventilation for hypercapnic acute respiratory failure. Crit Care Med 2009;37(1):124-131.

5. Navalesi P, Fanfulla F, Frigerio P, Gregoretti C, Nava S. Physiologic evaluation of noninvasive mechanical ventilation delivered with three types of masks in patients with chronic hypercapnic respiratory failure. Crit Care Med 2000;28(6):1785-1790.
6. Willson GN, Piper AJ, Norman M, Chaseling WG, Milross MA, Collins ER, Grunstein RR. Nasal versus full face mask for noninvasive ventilation in chronic respiratory failure. Eur Respir J 2004; 23(4):605-609.

7. Priou P, Hamel JF, Person C, Meslier N, Racineux JL, Urban T, Gagnadoux F. Long-term outcome of noninvasive positive pressure ventilation for obesity hypoventilation syndrome. Chest 2010;138(1): 84-90.

8. Storre JH, Bohm P, Dreher M, Windisch W. Clinical impact of leak compensation during non-invasive ventilation. Respir Med 2009; 103(10):1477-1483.

9. Saatci E, Miller DM, Stell IM, Lee KC, Moxham J. Dynamic dead space in face masks used with noninvasive ventilators: a lung model study. Eur Respir J 2004;23(1):129-135.

10. Cuvelier A, Pujol W, Pramil S, Molano LC, Viacroze C, Muir JF. Cephalic versus oronasal mask for noninvasive ventilation in acute hypercapnic respiratory failure. Intensive Care Med 2009;35(3):519526.

11. Fernández-Alvarez R, Rubinos-Cuadrado G, Cabrera-Lacalzada C, Galindo-Morales G, Gullón-Blanco JA, González-Martín I. [Home mechanical ventilation: dependency and burden of care in the home]. Arch Bronconeumol 2009;45(8):383-386. Article in Spanish.

12. de Lucas-Ramos P, de Miguel-Díez J, Santacruz-Siminiani A, González-Moro JM, Buendía-García MJ, Izquierdo-Alonso JL. Benefits at 1 year of nocturnal intermittent positive pressure ventilation in patients with obesity-hypoventilation syndrome. Respir Med 2004; 98(10):961-967.

13. Criner GJ, Brennan K, Travaline JM, Kreimer D. Efficacy and compliance with noninvasive positive pressure ventilation in patients with chronic respiratory failure. Chest 1999;116(3):667-675.

This article is approved for Continuing Respiratory Care Education credit. For information and to obtain your CRCE

(free to AARC members) visit www.rcjournal.com 